\title{
Qigong training as a successful factor of fighter's personal qualities development in students
}

\author{
Kudryavtsev M. D. ${ }^{1,2,3,5 \mathrm{ABCDE}}$, Kramida I. E. ${ }^{1,2 \mathrm{ABCDE}}$, Kopylov Yu.A. ${ }^{6 A B C D E}$, Osipov A.Yu. ${ }^{1,4,5 \mathrm{ABCDE}}$, Markov K.K. ${ }^{\text {7BCDE }}$, \\ Savchuk A. N. ${ }^{3 \mathrm{BCDE}}$, Kuzmin V.A. ${ }^{1 \mathrm{BCDE}}$ \\ ${ }^{1}$ Department of Valeology, Department of Physical Culture, Siberian Federal University, Russia \\ ${ }^{2}$ Department of Physical Education, Reshetnev Siberian State University of Science and Technology, Russia \\ ${ }^{3}$ Department of Theoretical Foundations of Physical Education, Krasnoyarsk State Pedagogical University named \\ after V.P. Astafiev, Russia \\ ${ }^{4}$ Department of Physical Culture, Professor V.F. Voino-Yasenetsky Krasnoyarsk State Medical University, Russia \\ ${ }^{5}$ Department of Physical Training, The Siberian Law Institute of the Ministry of Internal Affair of Russia, Russia \\ ${ }^{6}$ Laboratory of Innovative Technologies, The Center of natural science of physical education, Russia. \\ ${ }^{7}$ Department of Physical Culture, National Research Irkutsk State Technical University, Russia
}

Authors' Contribution: A - Study design; B - Data collection; C - Statistical analysis; D - Manuscript Preparation; E - Funds Collection

\begin{abstract}
Purpose: the analysis of fighter's personal qualities development in students in the course of teaching and educational Qigong training.

Material: $\quad$ students who actively attended standard physical culture classes participated in the research (group N1, $\mathrm{n}=101$, the 3rd course); students with a debilitated general condition who practiced the program of Qigong training within 1-3 years (group N2, $n=211$ ). It was fixed: the level of fighter's qualities development; a self-assessment (students estimated the level of fighter's personal qualities development according to the scale from 0 to 10 points).

Results: $\quad$ Development of 6 main fighter's personal qualities in students of group N1 was more successful and fast than in students of group N2. The average result on all 6 fighter's personal qualities increases significantly and consistently with the increase in duration of training.

Conclusions: Qigong training is an important factor in fighter's personal qualities development in students. In general, it is necessary to develop the health culture which becomes the way of maintaining a constant healthy lifestyle in students. It is necessary that male with strong-willed fighter's qualities always sought to participate in the long physical self-improvement.

Keywords: $\quad$ students, physical culture, Qigong-training, fighter's personal qualities
\end{abstract}

\section{Introduction}

In all oriental martial arts, a huge significance is attached to the development of the fighter's identity. Before initial martial arts training, it is necessary to develop a set of personal qualities. Without such qualities, the fighter won't be successful in a fight. Moreover, he won't be allowed to the knowledge of the deep secrets of martial art. In the Chinese martial art wushu, the system of development of identity bases of the future fighter is based on the gymnastics Qigong. In other oriental martial arts, there are similar systems of exercises.

There is a set of the personal qualities necessary for the fighter for constant victories. It is possible to extract the six most important qualities among them. Each of them is integrative. They include several private characteristics - traits of character or person's abilities. They are: 1) positivity or the positive relation to life (ability to learn from owns mistakes, optimism, etc.); 2) emotional stability (fearlessness, tranquility, lack of vulnerability, anxiety, irritability); 3) generosity in the attitude to other people (ability to understand and accept other people, friendliness, low aggression); 4) confidence (high self-assessment, independence, lack of inferiority complexes, etc.); 5) activity (consistency of aim, vital activity, etc.); 6) developed self-checking (consciousness

\footnotetext{
(C) Kudryavtsev M. D., Kramida I. E., Kopylov Yu.A., Osipov

A.Yu., Markov K.K., Savchuk A. N. , Kuzmin V.A., 2018

doi:10.15561/20755279.2018.0404
}

in actions, self-perception as a person, ability to get rid off unnecessary emotions and thoughts etc.).

The most of students at our university are trained in physical culture classes. Such training includes gamesbased sports training, swimming, gymnastics, etc. But a part of students is trained on physical culture according to the program of specialization "Improving Qigongtraining". Generally, they are those students with a debilitated general condition.

This program provides training on which students perform special improving exercises: relaxation and articulate warm-ups; Chinese gymnastics Qigong; selfcontrol exercises [1].

It is important to study features of sports activity influence on the identity of males and females. It is revealed that sports activities influence the identity of males and females was ambiguous. It is proved the interdependence of indicators of culturological parameters. The interrelation of factors of the athletes' identity of various classification groups of sports and sports disciplines is also proved [2].

It was carried out own researches [3] and modern perspective researches [4] concerning the subject of the article. Scientists found out the degree of study influence at the university on the prevalence and strength of unhealthy habits in students. These researches determined that there is an urgent need to search the means and a solution to the problem of unhealthy habits impact on the 
identity of students [5]. Such habits cause certain threats to students and distract them from study preparation. The entertaining websites and abundance of modern computer games demand a huge amount of time. All this causes threats to loss of education level. Similar habits lead to loss of concentration on the priority life directions. The modern student has to develop fighter's special personal qualities. It is necessary to be able to resist life difficulties and to fight against unhealthy habits [6].

Many students have the debilitated general condition. The youth chooses active receiving modern higher education. Thereby the youth sacrifices the health. The healthy lifestyle becomes secondary. Students give up on sports hobbies. Consequently, the amount of incidences increases among students. The level of physical fitness decreases in youth. The number of the students who have a medical exemption from physical education for health reasons increases.

The fighter's personal qualities develop in students in physical culture training. There are substantial grounds to believe that most of all it is shown in Qigong-training. These qualities develop more effectively under the influence of Qigong-training. Earlier we carried out the analysis of students' personal development in the course of their Qigong-training [7]. The received results demonstrate high efficiency of Qigong-training for the general development of student's identity. However, no studies had been conducted concerning the Qigongtraining influence on the development of fighter's personal qualities.

At the same time, there are some similar foreign researches on this subject. For example, concerning selfmanagement as a condition for health culture creation among students. In this case, it is considered the formation of self-management skills for creating a new relation. It promotes the development of innovative processes in training and to use of skills of maintaining a healthy lifestyle by students [8]. It is very important to investigate the quality of life of students. It is also important to track a possibility of the greatest disclosure of the human capital in the course of activization of global processes in society [9]. Authors have revealed that:

- Found brain activation patterns result from different attentional focusing styles and breathing techniques performed during the investigated Health Qigong techniques [10];

- Dynamic and static body postures are a defining characteristic of mind-body practices such as Tai Chi and Qigong (TCQ). A growing body of evidence supports the hypothesis that TCQ may be beneficial for psychological health, including management and prevention of depression and anxiety [11];

- Baduanjin, a Chinese traditional Qigong exercise that focuses on a mind-body integration, is considered to be an effective exercise in promoting health [12];

- Mindfulness-based Baduanjin exercise may be effective for alleviating musculoskeletal pain and improving overall sleep quality in people with chronic illness [13].
According to our point of view, self-government of students gives the chance to turn strong-willed selfrealization into a requirement. Students will be able to continue skills of healthy life for many years. The mission of the trainer on sports and the teacher of physical culture, in this case, is concentrated on the development of the identity of the student. Any more only full implementation of the program of training isn't the main thing. Proceeding from these prerequisites in training, it is necessary to create for students of knowledge, ability, and skills. Then it is possible to guarantee healthy self-development and consciousness of the modern young man.

In foreign researches the idea that intellectual and sports activity of students has to be the best by results in certain age reveals. At the same time, in a research features of such an educational process are emphasized. In this case, all results for the student turn out under pressure of teachers on their personality. The same can be noted also for the results of athletes achieved under the influence of trainers. In this case athletes, students are exposed to physical and psychological abuse. It most often occurs during preparation for competitions [14].

Foreign researchers study the most important factors for the improvement of intellectual and physical activity of students. In this case, resistance to social problems is investigated. It is the result of the compliance of level of physical health and a psycho-emotional condition of students $[15,16]$. In other researches, it is established that:

- Both males and females with high cognitive load scores had a non-significant trend toward higher BMIs, waist circumferences, and drinking more alcohol than low cognitive load counterparts [17];

- Abusive use of video games is associated with negative health consequences, such as musculoskeletal problems, eye disease, or cognitive and emotional problems. Therefore, it is vital to promote a sport practice associated with intrinsic motivations in order to avoid sport abandonment and develop a more hedonistic practice to avert sedentary habits [18];

- Physical activity, health-related quality of life, selfconcept and body-mass index are indicators of a healthy lifestyle [19];

- Results show a dependent relationship between the acceptances of negative experiences and execution of physical activity. These results suggest a high probably of negative emotional experiences acceptance in people who makes intense or moderate physical activity [20];

- Electronic word-of-mouth on social network sites has been used successfully in marketing. In social marketing, electronic word-of-mouth about products as health behaviors has the potential to be more effective and reach more young adults than health education through traditional mass media. This study shed light on the application of the electronic word-of-mouth theoretical framework in promoting health behaviors. The findings can also guide the development of future social marketing interventions using social network sites to promote leisure-time 
physical activity [21].

The Polish scientists investigated a subjective profile of positive health and survival in the females with differing physical activity. The physical activity is the important factor influencing health and ability to survive. Researchers have studied how under the influence of physical activity things change in a condition of somatic and mental health of females [22-24].

Scientists investigated the role of "Qigong” gymnastics in a restoration of an organism in high-speed and power load. They have developed panacea of a restoration of nervous, respiratory, cardiovascular and muscular systems. It occurs after a tiresome load in training process by means of Qigong training. The “Qigong” gymnastics was included in a warm-up and in a final part of a training. It is proved that the application of "Qigong” gymnastics is very effective. Especially in the training process of the heaviest microcycle of the high-speed and power period. The Qigong is an additional reserve of quality improvement of an athlete's physical condition [25].

The method of self-assessment is very widespread in psychology and pedagogical researches [26-28]. In spite of this fact it is subjective and inexact. Young people with a low self-assessment have the low level of modern aspirations of the personality. Such students refuse any educational work with competitive elements [29, 30]. In the future life, such students will refuse for certain a positive spirit on successful vital self-realization. It is proved that in such cases the objective self-assessment is reached by the real attitude to the inner "I". In certain cases, it is reached by an uncertain assessment of own abilities. Everything depends on the community and collective demands. According to some researchers' point of views, the self-assessment is the main component in the structure of the personality. Only due to high self-esteem, young people will be able to find confidence in themselves. They will treat surrounding reality and transform it according to own opportunities and forces [31]. In our research, we have minimized the influence of these factors.

The research hypothesis. It was assumed that improving Qigong training is an important factor of development of fighter's personal qualities development in students. They promote the improvement of fighter's personal qualities in all groups of the students attending Qigong training. It occurs significantly higher than in students practicing other types of physical culture.

Purpose. To investigate the learning efficiency of students according to the Qigong training program for developing the fighter's personal qualities.

\section{Material and methods.}

Participants. Two groups of the students who actively attending physical culture training at the university $(n=101)$ and Qigong training $(n=277)$ were created for carrying out a research. Experimental groups consist of the students who trained according to the Qigong training program during 1, 2 and 3 years (volumes of samples respectively 167, 66 and 44 persons). As control groups, we considered the students attending ordinary physical culture training at the university during three years $(\mathrm{n}=101)$.

Organization of a research. In an experiment were fixed fighter's personal qualities development in students of experimental and control groups at the beginning of training and at the end of training of the corresponding academic year. Earlier we proved that such students have the best indicators of positive personal qualities. Including fighter's personal qualities development in physical culture training during 1-3 courses [2].

At the end of the corresponding academic year, students of experimental and control groups were offered to estimate development degree of different personality qualities by a scale from 0 to 10 points. At the beginning and at the end of the training period students estimated private characteristics of each fighter's personal quality. It was very important to increase the objectivity of a research. As an indicator of the influence of Qigong training program on fighter's personal quality, we applied not absolute values of self-assessments of students. For this purpose was applied the difference between their estimation of the same quality value before training and during a research. For most of the young people, it is much easier to estimate the change in the development of personal qualities for any period of time. It is more difficult to do this and to estimate correctly extent of this development at present today.

We have the intentionally limited sample of participants in our research. It was only those students who are able to fix and estimate consciously the development and dynamics of development of own personal qualities. We were interested in those students who in the next 10-20 years can become chiefs of a different level. One of the tasks of this method is an increase in the consciousness of young people [1].

Statistical analysis. It was carried out the primary mathematical processing of results of each student: 1) calculation of a difference of final and initial estimates of each of private characteristics of each main quality of the fighter's identity - growth of estimates during training (as positive assessment of negative quality was accepted size $10-\mathrm{N}$, where - is an assessment of development extent of negative quality); 2) calculation of average value of estimates growth of the separate qualities of the personality which are manifestations of each of six main fighter's personal qualities.

It was applied the following statistical methods of data processing: 1) calculation of average values of estimates' growth of the main fighter's personal qualities for each group of students; 2) estimation of the reliability of differences between average values according to Student criterion. Differences were accepted as essential at significance value less than 0,05 .

\section{Results.}

The final table of estimates' average growth of six main fighter's personal qualities development is given below: 1) in the 3rd year students who trained on ordinary physical culture classes; 2) in the students attending 
Table 1. Estimates' growth of total development of fighter's personal qualities in students

\begin{tabular}{|c|c|c|c|c|c|}
\hline \multirow{3}{*}{ Personal qualities } & \multirow{2}{*}{\multicolumn{4}{|c|}{$\begin{array}{l}\text { Estimates' growth in groups } \\
\pm(0-10) \text { points }\end{array}$}} & \multirow{3}{*}{ Important significant correlations } \\
\hline & & & & & \\
\hline & 3 & C1 & $\mathrm{C} 2$ & C3 & \\
\hline Positivity & $0,8 \pm 0,1$ & $1,2 \pm 0,1$ & $1,6 \pm 0,2$ & $2,6 \pm 0,2$ & $3^{\prime}<\mathrm{C} ; \mathrm{C} 3>\mathrm{A} 2>\mathrm{C} 1$ \\
\hline Emotional stability & $-0,2 \pm 0,1$ & $0,6 \pm 0,1$ & $1,0 \pm 0,1$ & $1,5 \pm 0,2$ & $3^{\prime}<\mathrm{C} ; \mathrm{C} 3>\mathrm{A} 2>\mathrm{A} 1$ \\
\hline Generosity & $0,3 \pm 0,1$ & $0,8 \pm 0,1$ & $1,0 \pm 0,1$ & $1,5 \pm 0,2$ & $3^{\prime}<\mathrm{C}$; $\mathrm{A} 3>\mathrm{A} 1, \mathrm{C} 2$ \\
\hline Confidence & $0,8 \pm 0,1$ & $1,0 \pm 0,1$ & $1,6 \pm 0,2$ & $2,3 \pm 0,2$ & ${ }^{\prime} 3{ }^{\prime}, \mathrm{C} 1<\mathrm{C} 2, \mathrm{C} 3$ \\
\hline Activity & $0,7 \pm 0,1$ & $1,0 \pm 0,1$ & $1,3 \pm 0,1$ & $1,3 \pm 0,1$ & ${ }^{\prime} 3{ }^{\prime}, \mathrm{C} 1<\mathrm{C} 2, \mathrm{C} 3$ \\
\hline Self-assessment & $0,8 \pm 0,1$ & $1,4 \pm 0,1$ & $1,8 \pm 0,2$ & $2,3 \pm 0,2$ & $3^{\prime}<\mathrm{C} ; \mathrm{C} 3>\mathrm{A} 2>\mathrm{C} 1$ \\
\hline Average values in all qualities & $0,5 \pm 0,1$ & $1,0 \pm 0,1$ & $1,4 \pm 0,1$ & $1,9 \pm 0,2$ & $3^{`}<\mathrm{C} ; \mathrm{C} 3>\mathrm{A} 2>\mathrm{C} 1$ \\
\hline
\end{tabular}

Note. Designations in the table: $\mathrm{C}$ - data of all groups of the students attending Qigong training classes; C 1, C 2, C 3 groups of the students attending Qigong training classes during 1, 2, 3 years respectively; 3 - data of group 3 (students who practicing other types of physical culture during three years).

Qigong training classes during the corresponding period of study (1, 2 or 3 years).

The pedagogical experiment has shown the following:

1. For all 6 main fighter's personal qualities the estimates' growth of all groups of the students attending Qigong training classes was significantly above, then in the students who practice other types of physical culture with the same term of study. Estimates' growth of development of all fighter's personal qualities in those who attended Qigong training classes during only one year: whether haven't a significant difference, or have significantly higher than in the students who practicing other types of physical culture during three years.

Average estimates' growth of all six fighter's personal qualities for the students studying according to the Qigong training program after the first year of study is significantly above that in the students who practice other types of physical culture during three years. It may safely be said that fighter's personal qualities development in students practicing Qigong training is more successful.

2. The average result on all six fighter's personal qualities development of three fighter's personal qualities (positivity, emotional stability, self-assessment) during the study of one, two and three years (C 1, C 2, C 3) is significantly and consistently grows. Estimates' growth of development of other fighter's personal qualities in students of the group C 3 (or groups C 3 and C 2) is significantly above this indicator in comparison with group C 1. It confirms that development of fighter's personal qualities in students during Qigong training grows with the increase in duration of training.

\section{Discussion}

It should be noted that in this research authors of article managed to single out the scientific perspective connected with a certain increase in consciousness of young people. Authors pay attention to very current problems in the education system of students [29]. It is proved that improving Qigong gymnastic [7] is a dynamic factor of personal component development [6] of a healthy lifestyle in students. The conducted research confirms a hypothesis of authors of the article about the development of personal qualities of the fighter in students practicing Qigong training [1] depending on study duration.

Our results confirm conclusions of other research that it is possible to influence the process of formation of students' health culture as a result of social, psychological, economic and social changes. Sports activity and vocational training of students has to be based on certain knowledge and physical activity. This activity has to have a certain purpose and develop the identity of the student [14].

Indirectly "Qigong” in the training process of the heaviest microcycle of the high-speed and power period confirms the main conclusions of the authors of the article concerning the application of gymnastics. It is proved also by other researches. It is an additional reserve of quality improvement of the athlete physical condition of the- the student. This factor influences the development of the identity of the fighter in athletes - students [25]. It will be coordinated with the main concept of authors of the article [22].

Our results are confirmed by other research, revealed features of the influence of sports activity on the identity of males and females in culturological aspect. It is necessary to consider the extent of the culturological impact of sports activity on personal features of athletes of a different gender. It is determined that the selfassessment is important for females. Factors of emotional and strong-willed and communicative spheres find the equal amount of interdependence. At men prevail reliable communications with indicators of the emotional and strong-willed sphere [2].

Our results [3] and researches of foreign authors confirm the existence of the designated problem and need of its further studying [15]. It is also very important to solve this perspective and in further similar researches [9]. Development of fighter's personal qualities in students should be studied by means of different types of sport. Therefore studying of influence on the personality 
practicing Qigong training has reasonable scientific prospects [4].

Thus, self-government of students [8] gives the chance to turn into requirement the strong-willed selfrealization of continuation of healthy life without modern addictions [5] for years to come. Trainers and teachers have to be concentrated on efforts on the development of the student's identity, but not on the organization and implementation of students training program. Thereby, there will be an increase in a self-assessment of students [31]. Young people will be able to find self-confidence. Due to development of strong-willed qualities of the fighter, they will be able to struggle with all vital difficulties. Our approaches are validated by other researches [32].

As the summary, it should be noted that the analysis of the received results allows to make an important conclusion. Researchers have proved the validity of a statement about the influence of training at the university with the application of Qigong training on the corresponding parameters of students' identity. On the basis of comparison of the obtained data in control and experimental groups, it is possible to draw positive conclusions on the main scientific idea of the article. For experts and modern young people becomes clear: what training is a more effective factor of fighter's personal qualities development in students.

\section{Conclusions}

1. The fighter's personal qualities develop in students during Qigong training program. The intensity of this development is higher than in students practicing other types of physical culture.

2. Development of fighter's personal qualities in students grows with the increase in duration of their study in Qigong training program.

3. Qigong training is an important factor of fighter's personal qualities development in students.

4. In general, it is necessary to develop the health culture which becomes a way of maintaining a constant healthy lifestyle at students for them. It is necessary that the young man with strong-willed combatively always sought to participate in the long physical self-improvement.

\section{Conflicts of interest}

The authors declare that there is no conflict of interests.

\section{References}

1. Kramida IE. Valeological practical work on the basis of the Chinese gymnastics Qigong for students of special medical group. International electronic scientific and practical conference "Physical training, sport, physical rehabilitation and recreation in higher educational institutions: problems and prospects of development", SIBGAU. Krasnoyarsk; 2011. P. 179 - 181. (in Russian)

2. Artamonova TV. The interdependance of culturological parameters`indicators and athletes` personality factors in different classificatory groups of types. Uchenye zapiski universiteta imeni P.F. Lesgafta, 2009; 7 (53): 6-10. (in Russian)

3. Kudryavtsev MD, Kramida IE, Osipov AY. Influence of monitor bad habits on healthy lifestyle of students. Journal of Theory and practice of physical culture, 2016; 16(6): 24 - 27. (in Russian)

4. Voiskounsky AE. Flow Experience in Internet mediated environments. Motivation, consciousness and self-regulation. NY.: Nova Science; 2012.

5. Shvedov GI, Druganova LP. Shaeva TV. Negative factors of computer influence on human health. Nauchno-medicinskij vestnik Central'nogo Chernozem'ia, 2008; 32:10-15. (in Russian)

6. Kramida IE. Positive personal changes in relatively healthy students of 1 - 3 courses. All-Russian konferensiya "Science and education”. Tomsk: TSPU; 2005; 3(4). P. 117 - 122. (in Russian)

7. Kramida IE. Wellness practicum based qigong as a dynamic factor of development of the healthy lifestyle personal component in students. Research Journal of International Studies, 2014; 4. (3): 103 - 105. (in Russian)

8. Zavydivska OI, Zavydivska NN, Khanikiants OV. Selfmanagement as a condition for creating a health culture among students. Journal of Physical Education and Sport, 2016; Suppl.1:592 - 597. doi:10.7752/jpes.2016.s1093

9. Zavydivska NN, Zavydivska OI. Quality of life as a basis for the development of human capital in terms of globalization. Bulletin of the University of Banking of the National Bank of
Ukraine, 2013; 3(18):300-304. (in Ukrainian)

10.Henz D, Schollhorn WI. Temporal Courses in EEG Theta and Alpha Activity in the Dynamic Health Qigong Techniques Wu Qin Xi and Liu Zi Jue. Frontiers in Psychology. 2018;8. doi:10.3389/fpsyg.2017.02291

11. Osypiuk K, Thompson E, Wayne PM. Can Tai Chi and Qigong Postures Shape Our Mood? Toward an Embodied Cognition Framework for Mind-Body Research. Frontiers in Human Neuroscience. 2018;12. doi:10.3389/fnhum.2018.00174

12.Zou LY, Pan ZJ, Yeung A, Talwar S, Wang CY, Liu Y, et al. A Review Study on the Beneficial Effects of Baduanjin. Journal of Alternative and Complementary Medicine. 2018;24(4):324-335. doi:10.1089/acm.2017.0241

13.Zou LY, Yeung A, Quan XF, Boyden SD, Wang HR. A Systematic Review and Meta-Analysis of MindfulnessBased (Baduanjin) Exercise for Alleviating Musculoskeletal Pain and Improving Sleep Quality in People with Chronic Diseases. International Journal of Environmental Research and Public Health. 2018;15(2). doi:10.3390/ijerph15020206

14.Larion A. Tehnici specifice de predare-note de curs [Specific teaching techniques - course notes]. ConstanŃa: Ovidius University Press; 2007. (In Romanian)

15.Pitta F, Troosters T, Spruit MA, Probst VS, Decramer M, Gosselink R. Characteristics of physical activities in daily life for people with chronic obstructive pulmonary disease. American journal of respiratory and critical care medicine, 2010; 171(9): 972-980.

16.Korobeynikov G, Mazmanian K, Korobeynikova L, Jagiello W. Psychophysiological states and motivation in elite judokas. Archives of Budo. 2010;6(3):129-36.

17.Byrd-Bredbenner C, Quick V, Koenings M, Martin-Biggers J, Kattelmann KK. Relationships of cognitive load on eating and weight-related behaviors of young adults. Eating Behaviors. 2016;21:89-94. doi:10.1016/j.eatbeh.2016.01.002

18.Cuberos RC, Ortega FZ, Sanchez MC, Garces TE, Martinez AM, Cortes AJP. Motivational climate in sport and its relationship with digital sedentary leisure habits in university students. Saude E Sociedade. 2017;26(1):29-39. doi:10.1590/ s0104-12902017166561 
19.Palomino-Devia C, Reyes-Oyola FA, Sanchez-Oliver A. Levels of physical activity, health-related quality of life, physical self-concept and body-mass index among Colombian students. Biomedica. 2018;38(2):224-231. doi:10.7705/biomedica.v38i0.3964

20.Sanabria-Ferrand PA, Robledo SP. Relationship between the presence of experiential avoidance and the level of physical activity of university students. Revista De Psicologia Del Deporte. 2017;26(2):119-122.

21.Zhang N, Campo S, Yang JZ, Eckler P, Snetselaar L, Janz K, et al. What Motivates Young Adults to Talk About Physical Activity on Social Network Sites? Journal of Medical Internet Research. 2017;19(6). doi:10.2196/jmir.7017

22.Jagiełło W, Sawczyn S, Jagiełło M. The subjective profile of positive health and survival abilities in women differing as to physical activity. Archives of Budo, 2012; 8: 4-10.

23.Leonska-Duniec A, Grzywacz A, Jastrzebski Z, Jazdzewska A, Lulinska-Kuklik E, Moska W, et al. ADIPOQ polymorphisms are associated with changes in obesityrelated traits in response to aerobic training programme in women. Biology of Sport. 2018;35(2):165-173. doi:10.5114/ biolsport.2018.72762

24.Leonska-Duniec A, Jastrzebski Z, Jazdzewska A, Moska W, Lulinska-Kuklik E, Sawczuk $M$, et al. Individual Responsiveness to Exercise-Induced Fat Loss and Improvement of Metabolic Profile in Young Women is Associated with Polymorphisms of Adrenergic Receptor Genes. Journal of Sports Science and Medicine. 2018;17(1):134-144.

25.Khomyakov GK, Kosygina LV, Demidov AG, Utiasheva IM. Gymnastics "chi kung” as a factor in the recovery of speed and power within training period of the athletes. Uchenyye zapiski universiteta imeni P. F. Lesgafta. 2013;7 (101): 162169. (in Russian)

26.Jagiello W, Kalina RM, Tkachuk W. Age peculiarities of speed and endurance development in young judo athletes. Biology of Sport. 2001;18(4):281-295.

27.Romanenko V, Podrigalo L, Iermakov S, Rovnaya O, Tolstoplet E, Tropin Y, et al. Functional state of martial arts athletes during implementation process of controlled activity - comparative analysis. Physical Activity Review. 2018;6:8793. doi:10.16926/par.2018.06.12

28.Osipova A, Kudryavtsev M, Koptev O, Iermakov S, Bliznevskaya V. Contest coefficients of the elite judo athletes of Russia and Kyrgyzstan (less than $60 \mathrm{~kg}, 66 \mathrm{~kg}, 73 \mathrm{~kg}$ and $81 \mathrm{~kg}$ ) from 2010 till 2015. International Journal of Applied Exercise Physiology. 2018;7(2):32-45. doi:10.22631/ijaep. v7i2.267

29.Konstantinovskij DL, Cherednichenko GA. Current problems of education. 2010. (in Russian)

30.Jagiełło M, Iermakov SS, Nowiński M. Differentiation of the somatic composition of students physical education specialising in various sports. Arch Budo Sci Martial Art Extreme Sport, 2017;13:63-70.

31.Liashenko VN, Maris'kina TV. The comparative analysis of gender features of psychological protection at the athletes specializing in jumps. Scientific and practical conference of school students, students, undergraduates, graduate students "Modern problems of physical culture and sport", 2014. P. 223-227. (in Russian)

32.Wasik J, Wojcik A. Health in the context of martial arts practice. Physical Activity Review, 2017; 5: 91-94. doi:10.16926/par.2017.05.13

Information about the authors:

Kudryavtsev M.D.; (Corresponding author); http://orcid.org/0000-0002-2432-1699; kumid@yandex.ru; Siberian Federal University; 79 Svobodny pr., Krasnoyarsk, 660041, Russia; Krasnoyarsk State Pedagogical University named after V.P. Astafyev; Ady Lebedevoy Street, 89, Krasnoyarsk, 660049, Russia; The Siberian Law Institute of the Ministry of Internal Affair of Russia; Rokossovsky str., 20, Krasnoyarsk, 660131, Russia.

Kramida I.E.; http://orcid.org/0000-0003-4256-2645; Reshetnev Siberian State University of Science and Technology; Office A-406, 31, Krasnoyarsky Rabochy Av., 660014, Krasnoyarsk, Russia; Siberian Federal University; 79 Svobodny pr., Krasnoyarsk, 660041, Russia.

Kopylov Yu.A.; http://orcid.org/0000-0002-3925-0483; The Center of Natural Science of Physical Education, Moscow, Russia. Semenovskaya embankment, 3/1, Kor. 4105094, Moscow, Russia.

Osipov A.Yu.; http://orcid.org/0000-0002-2277-4467; Siberian Federal University; 79 Svobodny pr., Krasnoyarsk, 660041, Russia; Professor V.F. Voino-Yasenetsky Krasnoyarsk State Medical University, P. Zeleznyak, 1, Krasnoyarsk, 660022, Russia; The Siberian Law Institute of the Ministry of Internal Affair of Russia, Rokossovskia str., 20, Krasnoyarsk, 660131, Russia.

Markov K.K.; http://orcid.org/0000-0003-1893-5907; National Research Irkutsk State Technical University; ul. Lermontova, 83, Irkutsk, 664074, Russia.

Savchuk A. N.; http://orcid.org/0000-0003-0639-6950; Krasnoyarsk State Pedagogical University named after V.P. Astafyev; Ady Lebedevoy Street, 89, Krasnoyarsk, 660049, Russia.

Kuzmin V.A.; http://orcid.org/0000-0002-4190-1628; Siberian Federal University, Siberian State Aerospace University; 79 Svobodny pr., Krasnoyarsk, 660041, Russia.

Cite this article as: Kudryavtsev MD, Kramida IE, Kopylov YuA, Osipov AYu, Markov KK, Savchuk AN, Kuzmin VA. Qigong - training as a successful factor in the development of personal qualities of a soldier in students. Physical education of students, 2018;22(4):190-195. doi:10.15561/20755279.2018.0404

The electronic version of this article is the complete one and can be found online at: http://www.sportedu.org.ua/index.php/PES/issue/archive

This is an Open Access article distributed under the terms of the Creative Commons Attribution License, which permits unrestricted use, distribution, and reproduction in any medium, provided the original work is properly cited (http://creativecommons.org/licenses/by/4.0/deed.en).

Received: 08.03.2018

Accepted: 02.04.2018; Published: 23.08.2018 